\title{
Психоемоційні та рухові розлади після півкульного ішемічного інсульту
}

\author{
ДВНЗ «Ужгородський національний університет», м. Ужгород, Україна
}

\begin{abstract}
Мета: оцінити вплив післяінсультного когнітивного дефіц̧иту та емоційного розладу у пацієнтів на відновлення в них рухової функиї

Матеріали та методи. Дослідження проводилось протягом 2015-2016 років на базі відділення судинної неврології Ужгородської центральної міської клінічної лікарні. Обстежено 132 хворих після півкульного ішемічного інсульту. Всім хворим проведено загальноклінічні обстеження, нейровізуалізаційне обстеження з проведенням МСКТ чи МРТ головного мозку, нейропсихологічне обстеження з використанням батареї тестів для оиінки когнітивних функиій, Госпітальної икали тривоги і депресії, функиіональне обстеження з використанням модифікованої Скандинавської шкали інсультів, шкали оцінки неврологічного дефіциту при інсульті Національного інституту здоров'я США, икали оцінки м'язової сили, модифікованої шкали спастичності Ашворта. Статистичну обробку матеріалів проводили при допомозі стандартного статистичного пакета "Microsoft Exel 2010".
\end{abstract}

Результати. У дослідженні взяли участь 132 пацієнтів після перенесеного півкульного ішемічного інсульту. Середній

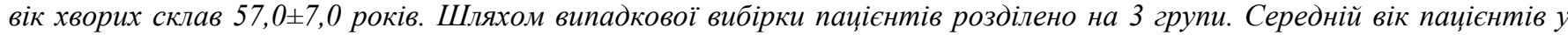

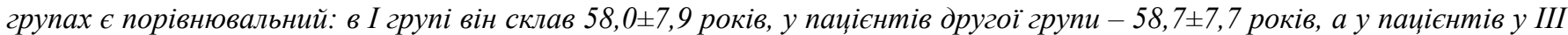

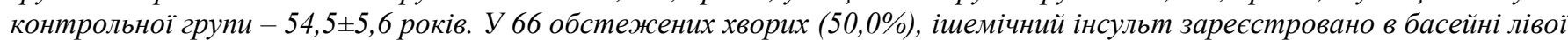
СМА, інсульт в басейні правої СМА теж у 66 пацієнтів. У першу та другу групи відібрано по 50 пацієнтів, а в третю - контрольну - 32 пачієнтів. Пацієнтам першої групи відновна терапія проводилась згідно протоколу лікування ішемічного інсульту з додаванням процедури магнітотерапї, пачієнти другої групи також проходили відновну терапію згідно протоколу, а разом з тим їм проводились процеедрри магнітотерапії, які поєднувалися з дзеркальною терапією. Контрольну групу склало 32 особи - изі пацієнти отримували відновну терапію згідно протоколу лікування ішемічного інсульту. Встановлено, щчо знижений настрій та висока тривожність сповільнює відновлення рухової активності та когнітивних функиій.

Висновки. Емоиійний стан, а саме пригнічений настрій сповільнює відновлення рухової активності, має виражений вплив на зміну показників шкали NIHSS, висока тривожність демонструвала кореляційний зв'язок із гіршою динамікою відновлення рухових функцій рук за 6-бальною шкалою оцінки м'язової сили та була пов'язана із більш повільним відновленням когнітивних функиій, оцінених за допомогою спеціальних експериментально-психологічних завдань із використанням таблиць Шульте. Покращзення показників когнітивних функцій, а саме довільної уваги та швидкості розумової реакиії оцінених за допомогою спеціальних експериментально-психологічних завдань із використанням таблиць Шульте після півкульного інсульту може бути предиктором зменшення спастичності в м'язах рук та ніг. Вищі показники тесту на запам'ятовування 10 слів виявились пов'язаними із кращою динамікою за шкалою Ашворта для рук.

Ключові слова: півкульний ішемічний інсульт, емочійні порушення, когнітивні порушення, дзеркальна терапія.

\section{Вступ}

B гострому періоді інсульту рухові порушення спостерігаються у переважної більшості пацієнтів, зазвичай це геміпарез, який реєструється у 65\% випадків [4]. Через місяць після перенесеного інсульту вільно пересуватися можуть тільки 55,0\% пацієнтів [1]. Через півроку стійкий руховий дефект зберігається у 53,0\% пацієнтів, котрі перенесли інсульт [2]. Через рік після перенесеного інсульту сторонньої допомоги потребує кожний третій $(28,3 \%)$ пацієнт [3] Рівень повсякденної активності, що був до захворювання, зберігається тільки у 10\% пацієнтів, у 30\% пацієнтів - порушення мови, у 7-11\% пацієнтів має місце розлад тазових функцій [1].

Прогностичними факторами погіршення самообслуговування у терміні від 3 до 12 місяців, $є$ цукровий діабет, попередній інсульт, фібриляція передсердь [3], а також артеріальна гіпертензія, ішемічна хвороба серця, підвищений індекс маси тіла, депресія [1, 2] та когнітивні порушення [1].

Мета: оцінити вплив післяінсультного когнітивного дефіциту та емоційного розладу у пацієнтів на відновлення в них рухової функції

\section{Матеріали та методи}

3 метою вивчення характеру та ступеню рухового, когнітивного дефіциту та емоційного стану у пацієнтів, котрі перенесли півкульний ішемічний інсульт, нами проведено обстеження хворих, які знаходилися на лікуванні відділення судинної неврології Ужгородської центральної міської клінічної лікарні протягом 20152016 року. Обстежено 132 хворих, що перенесли півкульний ішемічний інсульт. Діагноз ішемічного МI ставився на основі вивчення скарг, даних анамнезу, неврологічного статусу, додаткових методів обстеження 
(лабораторних даних, методів нейровізуалізації, яку проводили при допомозі комп'ютерної томографії чи магнітно-резонансної томографії голови). Критеріями включення у дослідження були: збережена свідомість (15 балів за шкалою ком Глазго), вік до 74 років, відсутність на момент дослідження важких соматичних захворювань, а також збереженість функції мови та письма. Всім хворим проведено нейропсихологічне обстеження 3 використанням батареї тестів для оцінки когнітивних функцій: коротка шкала психічного статусу - Mini-mental State Examination (MMSE), батареї тестів для дослідження лобової дисфункції - Frontal Assessment Battery (FAB), Монреальської шкали оцінки когнітивних функцій (МоСА), спеціальних експериментально-психологічних завдань із використанням таблиць Шульте, тесту на запам'ятовування 10 слів, тесту малювання годинника, Госпітальної шкали тривоги і депресії. Функціональний дефіцит оцінювали за допомогою наступних шкал: шкала оцінки неврологічного дефіциту при інсульті Національного інституту здоров'я США (NIHSS), модифікована Скандинавська шкала інсультів (SSSG), шкалу оцінки м'язової сили (Peak and Braddom) та модифіковану шкалу спастичності Ашворта. Статистичну обробку матеріалів проводили при допомозі стандартного статистичного пакета "Microsoft Exel 2010" шляхом розрахунку кореляційних коефіцієнтів Пірсона та визначення їх статистичної значимості.

\section{Результати дослідження та їх обговорення}

У дослідженні взяли участь 132 хворих, жителів м. Ужгород, що перенесли півкульний ішемічний інсульт.

У 66 обстежених хворих (50,0\%), ішемічний інсульт зареєстровано в басейні лівої СМА, інсульт в басейні правої СМА теж у 66 пацієнтів. Середній вік хворих склав $57,0 \pm 7,0$ років. Шляхом випадкової вибірки пацієнтів розділено на 3 групи. Середній вік пацієнтів у групах $є$ порівнювальний: в I групі він склав $58,0 \pm 7,9$ років, у пацієнтів другої групи - 58,7 7,7 років, а у пацієнтів у III контрольної групи - 54,5 $\pm 5,6$ років.

У першу та другу групи відібрано по 50 пацієнтів, а в третю - контрольну - 32 пацієнтів. Пацієнтам першої групи відновна терапія проводилась згідно протоколу лікування ішемічного інсульту з додаванням процедури магнітотерапії, пацієнти другої групи також проходили відновну терапію згідно протоколу, а разом 3 тим їм проводились процедури магнітотерапії, які поєднувалися 3 дзеркальною терапією. Контрольну групу склало 32 особи - ці пацієнти отримували відновну терапію згідно протоколу лікування ішемічного інсульту.

Виходячи 3 поставлених завдань оцінки впливу післяінсультного когнітивного дефіциту та емоційного розладу у пацієнтів на відновлення в них рухової функції, досліджували методом кореляційного аналізу за Пірсоном.

Нами було виявлено, що зменшення часу при виконанні спеціальних експериментально-психологічних завдань із використанням таблиць Шульте після півкульного інсульту є предиктором кращої динаміки у напрямку зменшення спастичності в м'язах рук ( $\mathrm{r}=-0,21$, $\mathrm{p}<0,05)$ та ніг $(\mathrm{r}=-0,19, \mathrm{p}<0,05)$. Результати тесту на запам'ятовування 10 слів виявили зв'язок із кращою динамікою показників за шкалою Ашворта для м'язів рук $(\mathrm{r}=0,20, \mathrm{p}<0,05)$ та ніг $(\mathrm{r}=0,19, \mathrm{p}<0,05)$ (таблиця).

Табличя

Вплив когнітивного дефіциту на відновлення рухових функцій у паціснтів після півкульного ішемічного інсульту

\begin{tabular}{|c|c|c|c|c|c|c|}
\hline & MMSE & MoCA & FAB & $\begin{array}{l}\text { Таблиці } \\
\text { Шульте }\end{array}$ & $\begin{array}{c}\text { Тест на } \\
\text { запам'ято- } \\
\text { вування } \\
10 \text { слів }\end{array}$ & $\begin{array}{c}\text { Тест } \\
\text { малювання } \\
\text { годинника }\end{array}$ \\
\hline SSSG & $\begin{array}{c}\mathrm{r}=-0,06 \\
\mathrm{p}=0,50\end{array}$ & $\begin{array}{c}\mathrm{r}=-0,02 \\
\mathrm{p}=0,83\end{array}$ & $\begin{array}{l}\mathrm{r}=0,12 \\
\mathrm{p}=0,19\end{array}$ & $\begin{array}{c}\mathrm{r}=-0,11 \\
\mathrm{p}=0,22\end{array}$ & $\begin{array}{c}r=-0,06 \\
\mathrm{p}=0,52\end{array}$ & $\begin{array}{l}r=0,02 \\
p=0,79\end{array}$ \\
\hline NIHSS & $\begin{array}{c}\mathrm{r}=-0,03 \\
\mathrm{p}=0,73\end{array}$ & $\begin{array}{c}\mathrm{r}=-0,08 \\
\mathrm{p}=0,34\end{array}$ & $\begin{array}{c}\mathrm{r}=-0,09 \\
\mathrm{p}=0,29\end{array}$ & $\begin{array}{c}|\mathrm{r}|<0,01 \\
\mathrm{p}=0,99\end{array}$ & $\begin{array}{c}r=-0,02 \\
p=0,82\end{array}$ & $\begin{array}{c}r=-0,05 \\
p=0,59\end{array}$ \\
\hline 6-бальна шкала, рука & $\begin{array}{l}\mathrm{r}=0,03 \\
\mathrm{p}=0,74\end{array}$ & $\begin{array}{l}\mathrm{r}=0,10 \\
\mathrm{p}=0,24\end{array}$ & $\begin{array}{l}\mathrm{r}=0,09 \\
\mathrm{p}=0,29\end{array}$ & $\begin{array}{l}r=0,02 \\
p=0,83\end{array}$ & $\begin{array}{l}r=0,05 \\
p=0,60\end{array}$ & $\begin{array}{l}r=0,04 \\
p=0,69\end{array}$ \\
\hline 6-бальна шкала, нога & $\begin{array}{l}r=0,07 \\
p=0,45\end{array}$ & $\begin{array}{l}r=0,07 \\
p=0,40\end{array}$ & $\begin{array}{l}r=0,04 \\
p=0,63\end{array}$ & $\begin{array}{l}r=0,02 \\
p=0,83\end{array}$ & $\begin{array}{c}r=-0,05 \\
\mathrm{p}=0,54\end{array}$ & $\begin{array}{l}r=0,03 \\
p=0,75\end{array}$ \\
\hline Шкала Ашворта, рука & $\begin{array}{c}\mathrm{r}=-0,01 \\
\mathrm{p}=0,90\end{array}$ & $\begin{array}{l}\mathrm{r}=0,02 \\
\mathrm{p}=0,81\end{array}$ & $\begin{array}{l}\mathrm{r}=0,03 \\
\mathrm{p}=0,76\end{array}$ & $\begin{array}{c}\mathrm{r}=-0,21 \\
\mathrm{p}<0,05\end{array}$ & $\begin{array}{l}\mathrm{r}=0,20 \\
\mathrm{p}<0,05\end{array}$ & $\begin{array}{l}r=0,01 \\
p=0,89\end{array}$ \\
\hline Шкала Ашворта, нога & $\begin{array}{c}r=-0,04 \\
p=0,62\end{array}$ & $\begin{array}{c}|r|<0,01 \\
p=0,99\end{array}$ & $\begin{array}{c}r=-0,06 \\
p=0,47\end{array}$ & $\begin{array}{c}\mathrm{r}=-0,19 \\
\mathrm{p}<0,05\end{array}$ & $\begin{array}{l}r=0,19 \\
p<0,05\end{array}$ & $\begin{array}{c}r=-0,06 \\
p=0,49\end{array}$ \\
\hline
\end{tabular}

Комплексні показники когнітивних функцій по шкалах MMSE, MoCA та FAB не виявили сильного впливу на швидкість відновлення рухової функції. Можна припустити, що це було пов'язано з ступенем когнітивного дефіциту - пацієнти мали переважно помірні когнітивні порушення, пацієнти 3 вираженими когнітивними порушеннями не залучатись у дослідження, так як це ускладнювало проведення у них дзеркальної терапії. 
Дослідження впливу емоційного стану пацієнтів, що перенесли півкульний ішемічний інсульт на відновлення рухових та когнітивних функцій проводили за допомогою аналізу кореляцій між зміною показників рухових та когнітивних функцій за відповідними доменами Госпітальної шкали тривоги і депресії (Hospital anxiety and depression scale - HADS). Висока тривожність демонструвала зв'язок із гіршою динамікою відновлення рухових функцій рук за 6-бальною шкалою ( $\mathrm{r}=-0,17$, $\mathrm{p}<0,05)$. Вплив депресії був найбільш виражений на зміну оцінки за NIHSS, однак статистичної значимості досягнуто не було $(\mathrm{r}=0,17, \mathrm{p}=0,05)$. Підвищена тривожність після інсульту пов'язана із більш повільним відновленням когнітивних функцій, оцінюваних методом таблиць Шульте $(\mathrm{p}<0,05)$ (рис.).

Оцінюючи вплив тривоги та депресії на функцію руху та когнітивні функції у пацієнтів після півкульного ішемічного інсульту по інших шкалах сильних кореляційних зв'язків помічено не було: по шкалі NIHSS $(\mathrm{p}>0,05)$.

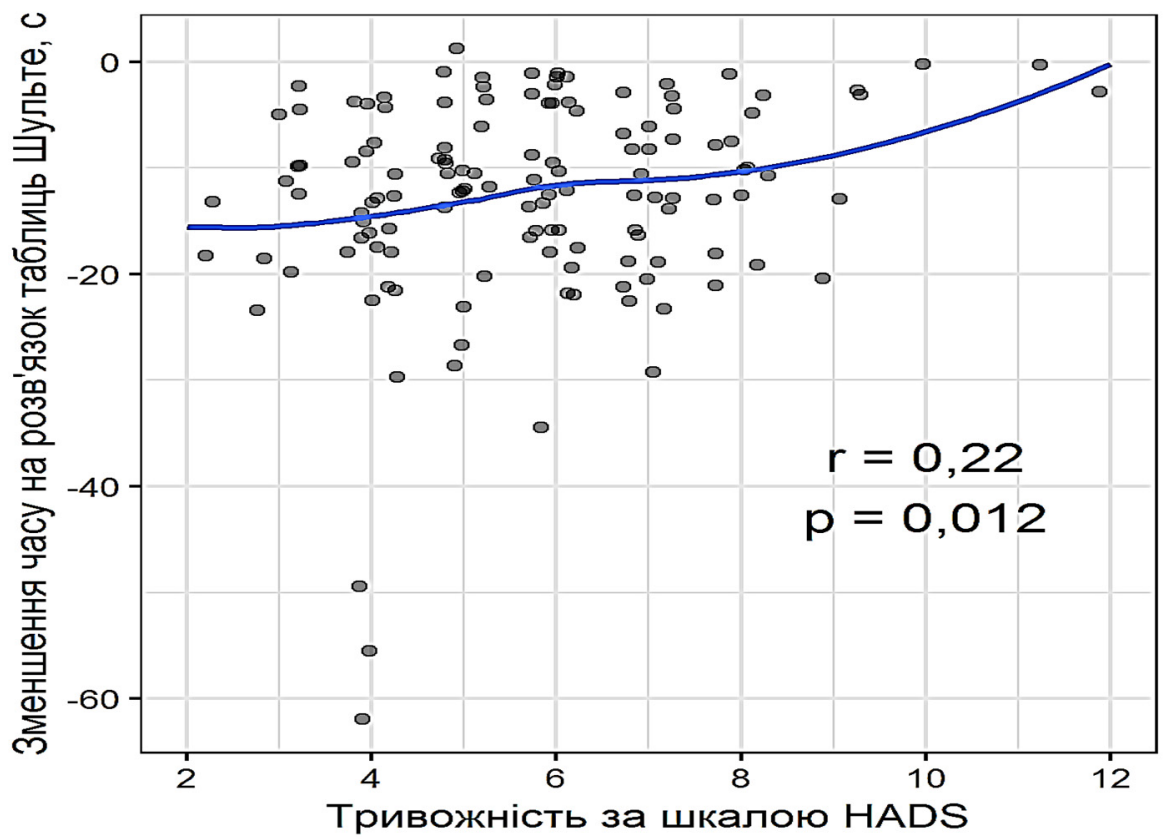

Рис. Залежність відновлення когнітивних функиій від емоиійного стану пацієнтів

\section{Висновки}

Підсумовуючи вищесказане можна зробити висновок, що емоційний стан, а саме пригнічений настрій сповільнює відновлення рухової активності, має виражений вплив на зміну показників шкали NIHSS, хоча статистичної значимості досягнуто не було ( $\mathrm{r}=0,17$, $\mathrm{p}=0,05)$. Висока тривожність демонструвала кореляційний зв'язок із гіршою динамікою відновлення рухових функцій рук за 6-бальною шкалою оцінки м'язової сили $(\mathrm{r}=-0,17, \mathrm{p}<0,05)$. Підвищена тривожність також була пов'язана із більш повільним відновленням когнітивних функцій, оцінених за допомогою спеціальних експериментально-психологічних завдань використанням таблиць Шульте $(\mathrm{r}=-0,22, \mathrm{p}<0,05)$

Покращення показників когнітивних функцій, а саме довільної уваги та швидкості розумової реакції оцінених за допомогою спеціальних експериментальнопсихологічних завдань із використанням таблиць Шульте після півкульного інсульту може бути предиктором зменшення спастичності в м'язах рук $(\mathrm{r}=-0,21, \mathrm{p}<0,05)$ та ніг $(\mathrm{r}=-0,19, \mathrm{p}<0,05)$. Вищі показники тесту на запам'ятовування 10 слів виявили зв'язок із кращою динамікою показників за шкалою Ашворта для м'язів рук $(\mathrm{r}=0,20, \mathrm{p}<0,05)$ та ніг $(\mathrm{r}=0,19, \mathrm{p}<0,05)$.

\section{Лiтература}

1. De Wit L., Putman K., Devos H. Five-year mortality and related prognostic factors after inpatient stroke rehabilitation: a European multi-centre study . J. Rehabil. Med. 2012. 44(7). P. 547-52.

2. Teasell R, Foley N, Salter K et al. Evidence-Based Review of Stroke Rehabilitation: Executive Summary, 12th Edition Journal topics in Stroke Rehabilitation Vol 16, 2009. Issue 6: Assessment in Stroke Rehabilitation. P $463-488$.

3. Ullberg T, Zia E, Petersson J, Norrving B. Changes in functional outcome over the first year after stroke: an observational study from the Swedish stroke register. Stroke. 2015 Feb;46(2):389-94.

4. Wist S, Clivaz J, Sattelmayer M. Muscle strengthening for hemiparesis after stroke: A meta-analysis. Annals of Physical and Rehabilitation Medicine.Vol 59, Issue 2, 2016, P 114-124. 


\section{Психоэмоциональные и двигательные расстройства после полушарного ишемического инсульта}

Гирявеи М.В., Пульк А.Р. ГВУЗ «Ужгородский национальный университет», г. Ужгород, Украина

Цель: оценить влияние постинсультного когнитивного дефицита и эмоционального расстройства у пациентов после полушарного ишемического инсульта на восстановление у них двигательной функции

Материалы и методы. Исследование проводилось в течение 2015-2016 г на базе отделения сосудистой неврологии Ужгородской центральной городской клинической больницы. Обследовано 132 больных после полушарного ишемического инсульта. Всем больным проведены общеклинические обследования, нейровизуализационных обследование с проведением МСКТ или МРТ головного мозга, нейропсихологическое обследование с использованием батареи тестов для оценки когнитивных функций, Госпитальной шкалы тревоги и депрессии, функциональное обследование с использованием модифицированной Скандинавской шкалы инсультов, шкалы оценки неврологического дефицита при инсульте Национального института здоровья США, шкалы оценки мышечной силы, модифицированной шкалы спастичности Ашворта. Статистическую обработку материалов проводили при помощи стандартного статистического пакета "Microsoft Exel 2010".

Результаты. В исследовании приняли участие 132 пациента после перенесенного полушарного ишемического инсульта. Средний возраст больных составил $57,0 \pm 7,0$ лет. Путем случайной выборки пациенты разделены на 3 группы. Средний возраст пациентов в группах является сравнительным: в I группе

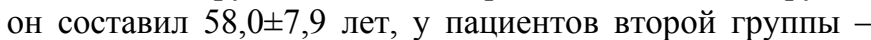
$58,7 \pm 7,7$ лет, а у пациентов III контрольной группы $54,5 \pm 5,6$ лет. В 66 обследованных больных (50,0\%), ишемический инсульт зарегистрировано в бассейне левой СМА, инсульт в бассейне правой СМА тоже в 66 пациентов. В первую и вторую группы отобраны по 50 пациентов, а в третью - контрольную - 32 пациентов. Пациентам первой группы восстановительная терапия проводилась согласно протоколу лечения ишемического инсульта с добавлением процедуры магнитотерапии, пациенты второй группы также проходили восстановительную терапию согласно протоколу, а вместе с тем им проводились процедуры магнитотерапии, которые сочетались с зеркальной терапией. Контрольную группу составило 32 человека - эти пациенты получали восстановительную терапию согласно протоколу лечения ишемического инсульта.

Установлено, что пониженное настроение и высокая тревожность замедляет восстановление двигательной активности и когнитивных функций.

Выводы. Эмоциональное состояние, а именно подавленное настроение замедляет восстановление двигательной активности, имеет выраженное влияние на изменение показателей шкалы NIHSS, высокая тревожность демонстрировала корреляционную связь с худшей динамикой восстановления двигательных функций рук по 6-бальной шкале оценки мышечной силы и была также связана с более медленным восстановлением когнитивных функций, оцененных с помощью специальных экспериментально-психологических задач с использованием таблиц Шульте. Улучшение показателей когнитивных функций, а именно произвольного внимания и скорости умственной деятельности оцененных при помощи специальных экспериментально-психологических задач с использованием таблиц Шульте после полушарного инсульта может быть предиктором уменьшения спастичности в мышцах рук и ног. Высокие показатели теста на запоминание 10 слов оказались связанными с лучшей динамикой по шкале Ашворта для рук.

Ключевые слова: полушарный ишемический инсульт, эмоциональные нарушения, когнитивные нарушения, зеркальная терапия.

\section{Psycho-emotional and motor dysfunction after hemispheric ischemic stroke}

Gyryavets M.V., Pulyk O.R. Uzhhorod National University, Uzhhorod, Ukraine

Purpose: to evaluate the effect of cognitive deficits and emotional dysfunction in patients after stroke on the restoration of their motor functions.

Materials and methods. The study was conducted during 2015-2016 at the Department of Vascular Neurology of Uzhhorod Central City Clinical Hospital. The study involved 132 patients with hemispheric ischemic stroke. All patients underwent general clinical examination, neuroimaging examination, neuropsychological examination using a battery of tests for the assessment of cognitive function, hospital anxiety and depression scale, functional examination using the NIHSS, Ashworth's modified spasticity scale, Muscle strength scale (Peak and Braddom). Statistical processing of materials was performed using the standard statistical package "Microsoft Exel 2010".

Results. The study involved 132 patients, residents of Uzhhorod, have suffered hemispheric ischemic stroke. The mean age of the patients was 57.0 \pm 7.0 years. By random selection, patients were divided into 3 groups. The mean age of the patients in the groups is comparative: in the first group it was $58.0 \pm 7.9$ years, in the patients of the second group $58.7 \pm 7.7$ years, and in the patients of the third control group $54.5 \pm 5.6$ years. In 66 patients $(50.0 \%)$, ischemic stroke was registered in the area of blood supply of left MCA, and also in the 66 patients of right MCA. 50 patients were selected in the first and second groups, and 32 patients in the third group. In the first group of patients, the treatment was performed according to the protocol of treatment of ischemic stroke with the addition of the magnetotherapy procedure, the patients of the second group also underwent treatment according to the protocol, and at the same time they underwent the magnetotherapy procedures and mirror therapy. The control 
group consisted of 32 individuals - these patients were treated according to the ischemic stroke treatment protocol. Low mood and high anxiety have been found to slow down the recovery of motor activity and cognitive function.

Conclusions. A depressed mood slows the recovery of motor function using the NIHSS scale. High anxiety revealed a correlation with poorer hand restoration dynamics on a 6-point muscle strength scale. Anxiety was associated with the slower recovery of cognitive functions assessed by the Schulte tables. Improvements in the cognitive performance assessed by the Schulte tables after hemispheric stroke have the effect of reducing the spasticity of the arm and leg by the Ashworth scale.

Key words: ischemic hemispheric stroke, emotional disorders, cognitive impairment, mirror therapy.

\section{Відомості про авторів}

Пулик Олександр Романович - д.мед.н, професор, завідувач кафедри нейрореабілітації із курсами медичної психології, пульмонології та фтизіатрії, факультет післядипломної освіти та доуніверситетської підготовки дВНЗ «Ужгородський національний університет»; пл. Народна, 3, м. Ужгород, Закарпатська обл., 88000, Україна.

Гирявець Мирослава Василівна - асистент кафедри нейрореабілітації з курсами медичної психології, пульмонології та фтизіатрії, факультет післядипломної освіти та доуніверситетської підготовки ДВНЗ «Ужгородський національний університет»; пл. Народна, 3, м. Ужгород, Закарпатська обл., 88000, Україна. 